\title{
Effects of porcine circovirus type 2 and pseudorabies vaccine co-inoculation on regulatory cytokine mRNA expression in pig peripheral blood mononuclear cells
}

\author{
F. Gao ${ }^{1,2}$, J.-L. Xie' ${ }^{1}$, C.-W. Jia ${ }^{1}$, H.-Y. Ren ${ }^{2}$ and S.-H. Zhou ${ }^{1}$ \\ ${ }^{1}$ College of Animal Science and Technology, Beijing University of Agriculture, \\ Changping District, Beijing, China \\ ${ }^{2}$ College of Animal Science and Technology, Qingdao Agricultural University, \\ Chengyang District, Qingdao Shandong, China \\ Corresponding author: S.-H. Zhou \\ E-mail: zhoushuanghai_b@163.com/shhaizhou@bac.edu.cn
}

Genet. Mol. Res. 13 (1): 1540-1547 (2014)

Received December 10, 2012

Accepted June 28, 2013

Published March 12, 2014

DOI http://dx.doi.org/10.4238/2014.March.12.6

\begin{abstract}
We investigated the immune response effects of porcine circovirus type 2 (PCV2) on cells inoculated with pseudorabies attenuated vaccine (PRV). Real-time PCR was used to detect the mRNA expression levels of the regulatory cytokines IL-4, IL-10, IL-12p40, and IFN- $\gamma$ in pig peripheral blood mononuclear cells, after in vitro single vaccination and co-inoculation with PCV2 and the PRV. We found that PRV causes upregulation of IL-4, IL-12p40, and IFN- $\gamma$ mRNA expression, while PCV2 causes mRNA upregulation of IL-4, IL-10, and IL-12p40. Moreover, PCV2 inhibited PRV-induced upregulation of IL-4, IL-12p40, and IFN- $\gamma$ mRNA expression; IFN- $\gamma$ mRNA expression was significantly inhibited. We conclude that PCV2 can reduce the cellular immune response to PRV.
\end{abstract}

Key words: Porcine circovirus type 2; Cytokine; Immune response; Pseudorabies attenuated vaccine 


\section{INTRODUCTION}

Porcine circovirus type 2 (PCV2) can cause multisystemic wasting syndrome resulting in reproductive failure, dermatitis, nephrotic syndrome, and respiratory disease after weaning (Hamel et al., 1998; Ellis et al., 1999; Opriessnig et al., 2007), and pseudorabies (PR) virus can cause reproductive failure and respiratory disease in pigs (Mettenleiter, 2000). These two pathogens have done great harm in the pig industry in China. PR vaccine (PRV) has shown a good protective effect, so vaccine immunization has become an effective mean for the prevention of pseudorabies around the world. However, the protective effect of PRV has decreased on PCV2-positive pig farms in recent years. The existing data have shown that PCV2 has immunosuppressive properties (Segalés et al., 2004) which can cause an imbalance in the expression of IL-4, IL-10, IL-12, IFN- $\gamma$, and other multiple cytokines (Darwich et al., 2003a,b). This will cause IL-10 mRNA upregulation and IFN- $\gamma$ mRNA downregulation in the peripheral blood mononuclear cell (PBMC) of pigs (Darwich et al., 2003a). IFN- $\gamma$ and IL-12 and IL-4 and IL-10 are important Th1- and Th2-type cytokines, respectively, and they play an important regulatory role in cellular and humoral immune responses, respectively. To investigate the effect of PCV2 on the PRV immune response, fluorescence quantitative PCR analysis was used to determine IL-4, IFN- $\gamma$, IL-10, and IL-12 mRNA expression in the PBMC of pigs after their inoculation with PCV2 and PRV in vitro.

\section{MATERIAL AND METHODS}

\section{Vaccine, virus, and plasmid}

PRV K-61 strains were from Boehringer Ingelheim (Berlin, Germany) $\left(10^{5.76} \mathrm{TCID}_{50}{ }^{\prime}\right.$ $\mathrm{mL})$ with the production batch number FA-953-224. PCV2 cytotoxic $\left(10^{5.82} \mathrm{TCID}_{50} / \mathrm{mL}\right)$, plasmids of the porcine cytokines IL-4, IL-10, IL-12, and IFN- $\gamma$ and some plasmids containing fragments of the house keeper $\beta$-actin gene were from the Animal Infectious Diseases Laboratory of the Animal Science and Technology Institute in Beijing University of Agriculture.

\section{Experimental animals}

Healthy landrace pigs, 38 days old, which were purchased from a farm in Beijing, were tested and found to be negative for PCV1, PCV2, and PR virus by PCR detection.

\section{Establishment of the cytokines fluorescent quantitative standard curve}

Five kinds of positive plasmid of porcine IL-4, IL-10, IL-12, IFN- $\gamma$, and $\beta$-actin were 10 -fold serially diluted into 8 -concentration gradients from $10^{8}$ to $10^{1}$ copies $/ \mu \mathrm{L}$. Real-time PCR was used with the respective specific primers (Table 1) to establish the standard curve of the cytokines. PCR was performed in $20 \mu \mathrm{L}$ containing following: $10 \mu \mathrm{L}$ SYBR ${ }^{\circledR}$ Green Real-time PCR Mix, 0.1 $\mu \mathrm{L}$ Rox buffer, $0.2 \mu \mathrm{L} 25 \mu \mathrm{M}$ upstream and downstream primer each, $1 \mu \mathrm{L}$ template, and $8.5 \mu \mathrm{L}$ triple-distilled water. The PCR procedure was as follows: $95^{\circ} \mathrm{C}$ for $5 \mathrm{~min}$ and 40 cycles of $95^{\circ} \mathrm{C}$ for $30 \mathrm{~s}, 56$ to $60^{\circ} \mathrm{C}$ for $30 \mathrm{~s}$, and $72^{\circ} \mathrm{C}$ for $30 \mathrm{~s}$. According to the variation of the fluorescence values, the system automatically generates a standard curve. 
Table 1. Sequences of the primers used for the detection of mRNA specific for cytokines and $\beta$-actin.

\begin{tabular}{lllcc}
\hline Gene & Accession No. & Primer sequence 5'-3' & Annealing temp. $\left({ }^{\circ} \mathrm{C}\right)$ & Amplicon (bp) \\
\hline IL-4 & X68330 & $\begin{array}{l}\text { Forward: ATCCCAACCCTGGTCTGC } \\
\text { Reverse: TCCTGTCAAGTCCGCTCA }\end{array}$ & 56 & 265 \\
IL-10 & L20001 & $\begin{array}{l}\text { Forward: GCATCCACTTCCAGGCCA } \\
\text { Reverse: CTTCCTCATCTTCATCGTCA }\end{array}$ & 60 & 452 \\
IL-12p40 & U08317 & $\begin{array}{l}\text { Forward: GATGCTGGCCAGTACACC } \\
\text { Reverse: TCCAGCACGACCTCAATG }\end{array}$ & 60 & 377 \\
IFN- $\gamma$ & X53085 & $\begin{array}{l}\text { Forward: CAGCTTTGCGTGACTTTGTG } \\
\text { Reverse: GATGAGTTCACTGATGGCTTT }\end{array}$ & 58 & 358 \\
$\beta$-actin & U07786 & $\begin{array}{l}\text { Forward: CTGGCATTGTCATGGACTCT } \\
\text { Reverse: GCGATGATCTTGATCTTCAT }\end{array}$ & 57 & 547 \\
\hline
\end{tabular}

\section{Experimental grouping}

Anticoagulated blood was obtained from the pigs and the PBMC were separated. The cell concentration in the culture medium was adjusted with $10 \%$ RPMI-1640 to $1 \times 10^{6} / \mathrm{mL}$, and they were then added to 12 -well cell culture plates, with $1 \mathrm{~mL}$ added to each well. Next, $0.1 \mathrm{~mL}$ PCV2 (PCV2 group), $0.1 \mathrm{~mL}$ PRV (PRV group), $0.1 \mathrm{~mL}$ PCV2 and $0.1 \mathrm{~mL}$ PRV (PCV2 + PRV group), and $0.1 \mathrm{~mL} \mathrm{10 \%} \mathrm{RPMI-1640} \mathrm{(control} \mathrm{group)} \mathrm{were} \mathrm{added.} \mathrm{Each} \mathrm{set} \mathrm{had}$ three repeats, and the cells were collected at different hours post inoculation (HPI).

\section{Real-time RT-PCR to detect the cytokine mRNA level}

Total cellular RNA was extracted with the TRIzol reagent (Invitrogen), and cDNA was synthesized by reverse transcription with Oligo (dT) ${ }_{15}$ according to the AMV instructions. $\beta$-Actin was amplified with the PCR method. The $\beta$-actin-positive samples were analyzed for IL-4, IL-10, IL-12, and IFN- $\gamma$ in real-time PCR.

\section{Statistical analysis}

SPSS 13.0 was used to perform the variance analysis, where $\mathrm{P}<0.05$ indicated a significant difference. The $2^{\triangle \Delta \mathrm{Ct}}$ method was used for the comparison of the cytokines in each group. $\Delta \Delta \mathrm{Ct}=(\mathrm{Ct} \text { target gene }-\mathrm{Ct} \text { housekeeping gene })_{\text {test group }}-(\mathrm{Ct}$ target gene $-\mathrm{Ct}$ housekeeping gene $)_{\text {control group }}, 2^{-\triangle \Delta \mathrm{Ct}}$ represents the fold-change of target gene expression in the test group compared to the control group.

\section{RESULTS}

\section{Establishment of the cytokine fluorescence quantitative PCR standard curve}

We took the different concentrations of recombinant plasmid as a template for realtime PCR and obtained the fluorescence quantitative PCR standard curve and its linear regression equation for the porcine cytokines IL-4, IL-10, IL-12, and IFN- $\gamma$ and the housekeeping gene $\beta$-actin. They were respectively as follows: $y=-3.149 \mathrm{x}+41.223, R^{2}=0.992 ; y=-4.5369 \mathrm{x}$ $+55.64, R^{2}=0.991 ; y=-3.6917 \mathrm{x}+55.959, R^{2}=0.997 ; y=-3.2304 \mathrm{x}+40.721, R^{2}=0.992 ;$ and 
$y=-3.189 \mathrm{x}+40.933, R^{2}=0.996$. The correlation coefficient of the standard curve was above 0.99 indicating that the standard curve was constructed successfully, and could be used for the quantitative measure of porcine IL-4, IL-10, IL-12, IFN- $\gamma$, and $\beta$-actin mRNA levels.

\section{IL-4 mRNA expression dynamics in the PBMC}

As seen in Figure 1, both PCV2 and PRV showed a significant $(\mathrm{P}<0.05)$ effect in enhancing IL-4 mRNA expression in pig PBMC at different times after inoculation. The mRNA expression in the PRV group was significantly higher than that in the PCV2 group at 72 HPI. At 24 HPI, the IL-4 mRNA expression level in the PCV2 + PRV group was significantly lower than that in the PCV2 group and PRV group. It showed that the PCV2 and PRV mixed stimulus had a certain antagonism effect; that is, PCV2 would suppress IL-4 mRNA expression upregulation induced by PRV in the early phase after inoculation.

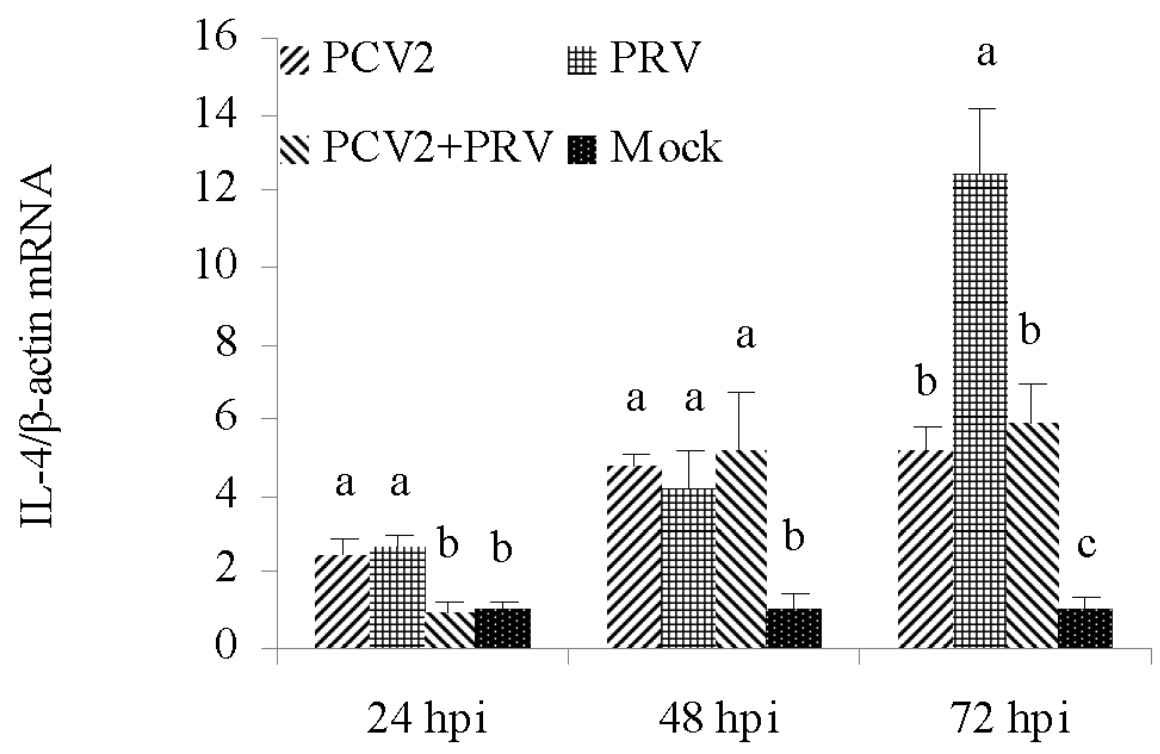

Figure 1. IL-4 mRNA levels in the PBMC at the different time after vaccination (Different letters indicate the significant difference of the inoculums results at the same time, it is the same below).

\section{IL-10 mRNA expression dynamics in the PBMC}

Compared with the control group, IL-10 mRNA expression in the PCV2 group and PCV2 + PRV group was significantly upregulated at different times after inoculation $(\mathrm{P}<$ 0.01). The increase in the latter group was below that in the PCV2 group, but there was no significant difference between the two groups $(\mathrm{P}>0.05)$. mRNA expression in the PRV group showed a significant increase compared with the control group only at 72 HPI $(\mathrm{P}<0.05)$, but there was no significant difference between the two groups (Figure 2). This indicated that PCV2 had a significant role in increasing IL-10 mRNA expression, where upregulation was not obvious with PRV. 


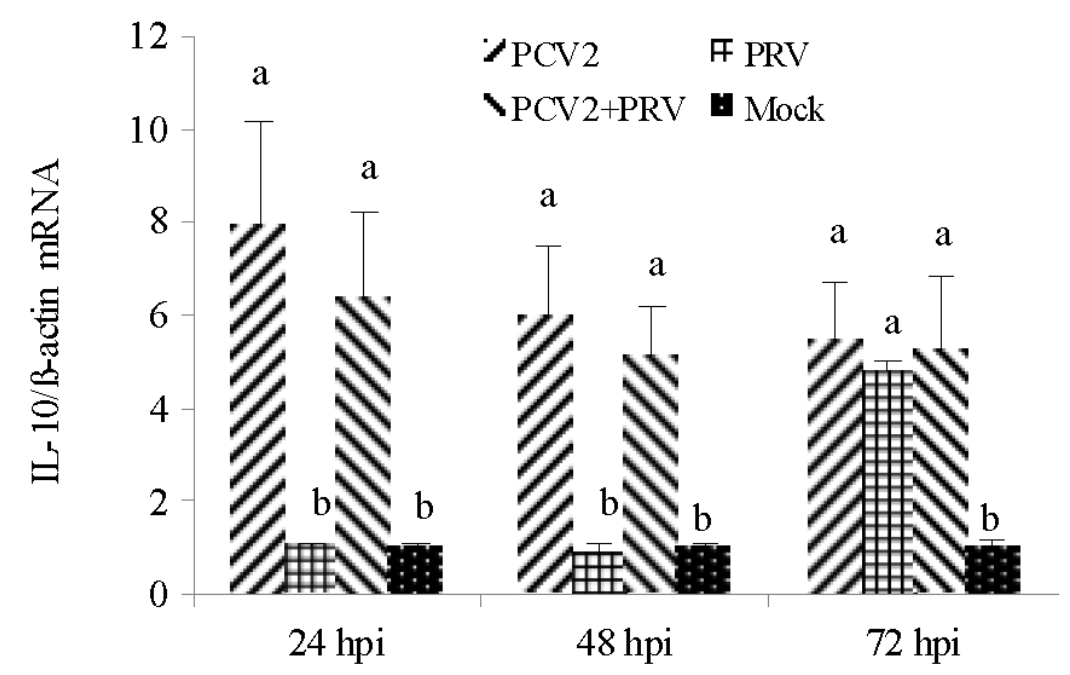

Figure 2. IL-10 mRNA levels in PBMC at different times after inoculation.

\section{IL-12p40 mRNA expression dynamics in PBMC}

As seen in Figure 3, PCV2 significantly increased IL-12p40 mRNA upregulation in porcine PBMC at different times after inoculation $(\mathrm{P}<0.05)$. At 24 and $48 \mathrm{HPI}$, PRV also showed the upregulation effect $(\mathrm{P}<0.05)$. However, the IL-12p40 mRNA expression level in the PCV2 + PRV group was significantly lower than that in the PCV2 group at 24 and 72 HPI, and it was significantly lower than that in the PRV group at 24 HPI. This indicated that PCV2 and PRV were capable of upregulating IL-12p40 mRNA expression, but there was a certain degree of the mutual antagonism between the two.

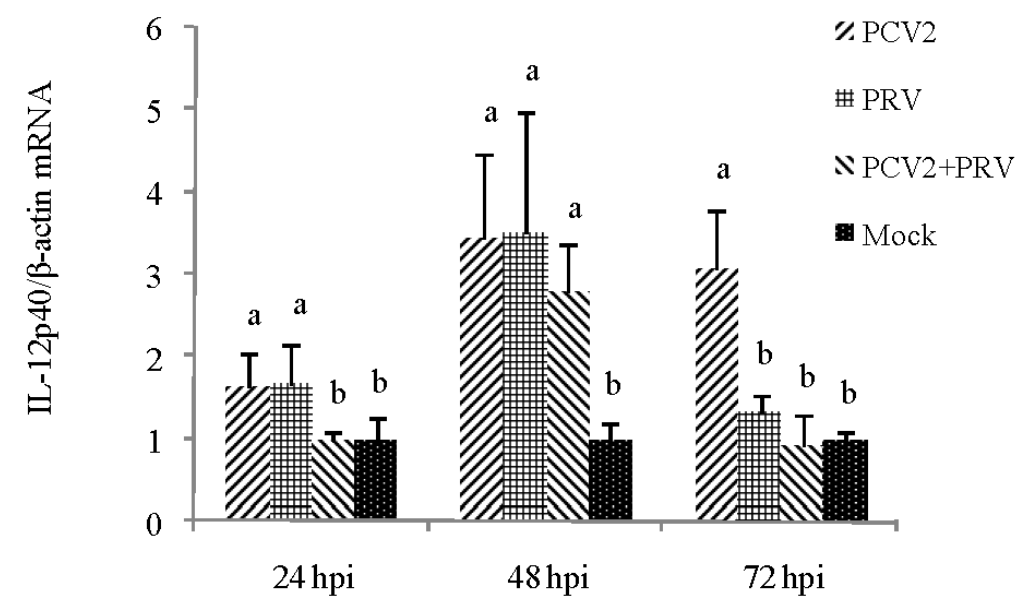

Figure 3. IL-12p40 mRNA levels in PBMC at different times after inoculation. 


\section{IFN- $\gamma$ mRNA expression dynamics in PBMC}

Compared with the control group at different times after inoculation, the average IFN- $\gamma$ mRNA level of the PCV2 group did not increase, but the IFN- $\gamma$ mRNA level of the PRV group showed a significant increase $(\mathrm{P}<0.05)$. The IFN- $\gamma$ mRNA level of PCV2+PRV group was significantly lower than that of the PRV group (Figure 4). This indicated that the PRV was able to upregulate IFN- $\gamma$ mRNA in PBMC. PCV2 did not have such an effect and, in contrast, significantly inhibited the upregulatory effect of PRV on IFN- $\gamma$ mRNA expression.

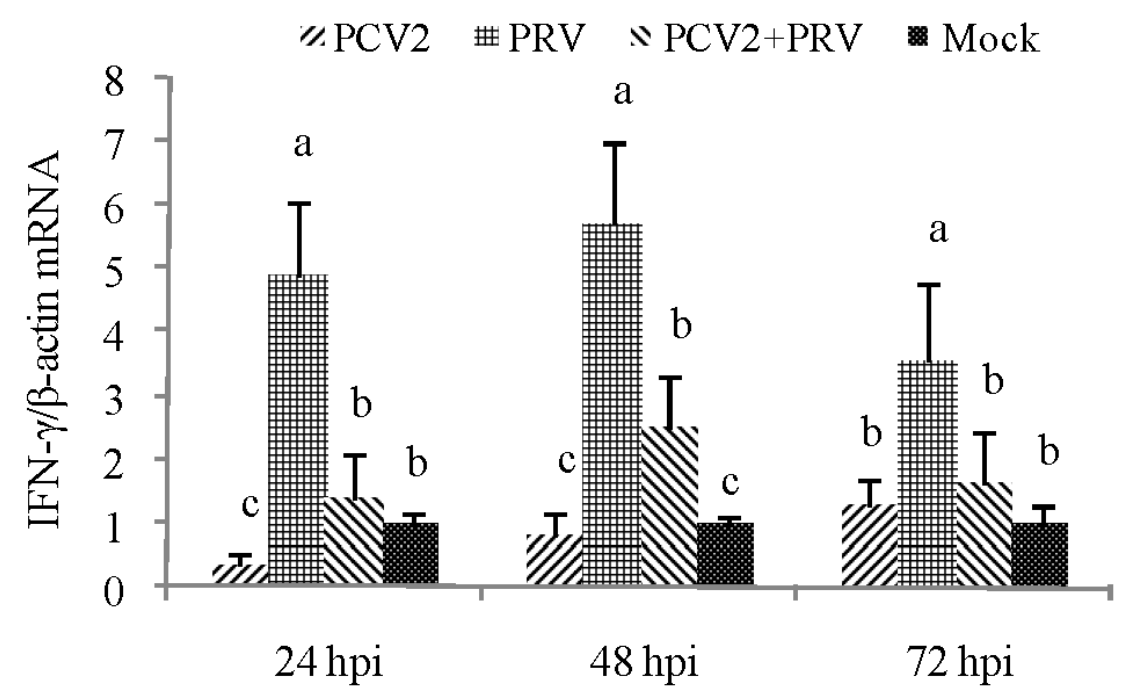

Figure 4. IFN-y mRNA levels in PBMC at different times after inoculation.

\section{DISCUSSION}

Existing data show that PCV2 has immunosuppressive characteristics that can cause an imbalance in a variety of cytokine mRNA expression (Segalés et al., 2004; Darwich et al., 2003a,b). Cytokines are important immune regulatory factors, where they play an important role in the immune network as signal molecules between cells. IL-12 and IFN- $\gamma$ are important Th1-type cytokines and have an important role in cellular immune response. IL-4 and IL-10 are important Th2-type cytokines and have an important role in humoral immune response.

Some studies on the PRV-immune pig PBMC in vitro have been reported (Kekarainen et al., 2008a,b); PCV2 and inactivated PRV are both able to induce the expression of IL-12, but they are only able to induce the mass expression of IL-10 and IFN- $\gamma$ separately. PCV2 can significantly inhibit the ability of inactivated PRV to induce IFN- $\gamma$ expression, but inactivated PRV does not inhibit the PCV2 from inducing IL-10 expression. The application of live PRV in vitro showed a consistent result. PCV2 induced mRNA upregulation of IL-4, IL-12 and especially IL-10 in PBMC, but it did not upregulate IFN- $\gamma$ mRNA expression. PRV can cause the mRNA expression upregulation of IL-4, IL-12, IFN- $\gamma$, but it is unable to cause IL-10 mRNA upregulation. Compared with single PRV vaccination, the PCV2 and PRV inocula- 
tion will cause the upregulation of IL-10 mRNA expression, downregulation of IFN- $\gamma$ mRNA expression and downregulation of IL-4 and IL-12 mRNA expression only in the early phase. This indicates that PCV2 and PRV show a mutual antagonism, mainly because that PCV2 significantly interferes with PRV-induced IFN- $\gamma$ mRNA expression. The results above showed that whether or not PRV underwent inactivation treatment, its ability to induce the expression of IL-10, IL-12, IFN- $\gamma$ and other cytokines in pig PBMC was the same. Although PCV2 had a certain effect on the expression of IL-12, its effect was mainly the suppression of IFN- $\gamma$ expression. In pig production, PRV-attenuated live vaccine and inactivated vaccine both have a good immune effect, where no significant difference was found between them. This may be good evidence that live PRV and inactivated PRV in vitro have the same effect on cytokine expression in pig PBMC.

Many studies have revealed that the induction of IL-10 upregulation is one of the basic characteristics of PCV2 (Darwich et al., 2003a; Segalés et al., 2004; Stevenson et al., 2006; Darwich et al., 2008). Our study further confirmed this phenomenon. It is known that over upregulation of IL-10 may cause immunosuppression. Kekarainen et al. (2008b) found that the PCV2-induced IL-10 decreased the immune response to recall antigens in the pig PBMC by participating in the inhibition of IFN- $\gamma$ expression. This indicates that IFN- $\gamma$ downregulation was the inevitable result of PCV2-induced IL-10 upregulation after the combined stimulation by PCV2 and PRV. Although PCV2 significantly inhibited PRV-induced expression of IFN- $\gamma$ in pig PBMC, its inhibitory effect on the expression of IL-4 was slight and transient. This suggested that PCV2 may primarily affect PRV cellular immune response of vaccinated pigs, but that its humoral immune response may not be obvious.

In summary, in the in vitro cell environment, PCV2 can significantly inhibit PRVinduced IFN- $\gamma$ mRNA expression in pig PBMC, suggesting that PCV2 may affect the cell immune response of PRV. The effects of PCV2 infection on the PRV immune response in vivo need to be further researched.

\section{ACKNOWLEDGMENTS}

Research supported by the Beijing Natural Science Foundation of China (\#6082008).

\section{REFERENCES}

Darwich L, Balasch M, Plana-Duran J, Segales J, et al. (2003a). Cytokine profiles of peripheral blood mononuclear cells from pigs with postweaning multisystemic wasting syndrome in response to mitogen, superantigen or recall viral antigens. J. Gen. Virol. 84: 3453-3457.

Darwich L, Pie S, Rovira A, Segales J, et al. (2003b). Cytokine mRNA expression profiles in lymphoid tissues of pigs naturally affected by postweaning multisystemic wasting syndrome. J. Gen. Virol. 84: 2117-2125.

Darwich L, Segales J, Resendes A, Balasch M, et al. (2008). Transient correlation between viremia levels and IL-10 expression in pigs subclinically infected with porcine circovirus type 2 (PCV2). Res. Vet. Sci. 84: 194-198.

Ellis J, Krakowka S, Lairmore M, Haines D, et al. (1999). Reproduction of lesions of postweaning multisystemic wasting syndrome in gnotobiotic piglets. J. Vet. Diagn. Invest. 11: 3-14.

Hamel AL, Lin LL and Nayar GP (1998). Nucleotide sequence of porcine circovirus associated with postweaning multisystemic wasting syndrome in pigs. J. Virol. 72: 5262-5267.

Kekarainen T, Montoya M, Dominguez J, Mateu E, et al. (2008a). Porcine circovirus type 2 (PCV2) viral components immunomodulate recall antigen responses. Vet. Immunol. Immunopathol. 124: 41-49.

Kekarainen T, Montoya M, Mateu E and Segales J (2008b). Porcine circovirus type 2-induced interleukin-10 modulates recall antigen responses. J. Gen. Virol. 89: 760-765. 
Mettenleiter TC (2000). Aujeszky's disease (pseudorabies) virus: the virus and molecular pathogenesis - state of the art, June 1999. Vet. Res. 31: 99-115.

Opriessnig T, Meng XJ and Halbur PG (2007). Porcine circovirus type 2 associated disease: update on current terminology, clinical manifestations, pathogenesis, diagnosis, and intervention strategies. J. Vet. Diagn. Invest. 19: 591-615.

Segalés J, Domingo M, Chianini F, Majo N, et al. (2004). Immunosuppression in postweaning multisystemic wasting syndrome affected pigs. Vet. Microbiol. 98: 151-158.

Stevenson LS, McCullough K, Vincent I, Gilpin DF, et al. (2006). Cytokine and C-reactive protein profiles induced by porcine circovirus type 2 experimental infection in 3-week-old piglets. Viral Immunol. 19: 189-195. 